\title{
Excellent response to pasireotide therapy in an aggressive and dopamine-resistant prolactinoma
}

\author{
Eva C Coopmans ${ }^{1, *}$, Sebastiaan W F van Meyel ${ }^{1, *}$, Kay J Pieterman ${ }^{2}$, Jolique A van Ipenburg ${ }^{3}$, Leo J Hofland ${ }^{1}$, \\ Esther Donga ${ }^{4}$, Adrian F Daly ${ }^{5}$, Albert Beckers ${ }^{5}$, Aart-Jan van der Lely' ${ }^{1}$ and Sebastian J C M M Neggers ${ }^{1}$
}

${ }^{1}$ Department of Internal Medicine, Endocrinology Section, Pituitary Center Rotterdam, Erasmus University Medical Center, Rotterdam, the Netherlands, ${ }^{2}$ Departments of Radiology and Medical Informatics, Biomedical Imaging Group Rotterdam, ${ }^{3}$ Department of Pathology, Erasmus University Medical Center, Rotterdam, the Netherlands, ${ }^{4}$ Department of Internal Medicine, Endocrinology Section, Elisabeth TweeSteden Hospital, Tilburg, the Netherlands, and ${ }^{5}$ Department of Endocrinology, University of Liège, Liège, Belgium

*(E C Coopmans and S W F van Meyel contributed equally to this work)

Correspondence should be addressed to E C Coopmans Email

e.coopmans@erasmusmc.nl

\begin{abstract}
Prolactinomas are the most commonly encountered pituitary adenomas in the clinical setting. While most can be controlled by dopamine agonists, a subset of prolactinomas are dopamine-resistant and very aggressive. In such tumors, the treatment of choice is neurosurgery and radiotherapy, with or without temozolomide. Here, we report a patient with an highly aggressive, dopamine-resistant prolactinoma, who only achieved biochemical and tumor control during pasireotide long-acting release (PAS-LAR) therapy, a second-generation somatostatin receptor ligand (SRL). Interestingly, cystic degeneration, tumor cell necrosis or both was observed after PAS-LAR administration suggesting an antitumor effect. This case shows that PAS-LAR therapy holds clinical potential in selective aggressive, dopamineresistant prolactinomas that express somatostatin (SST) receptor subtype 5 and appears to be a potential new treatment option before starting temozolomide. In addition, PAS-LAR therapy may induce cystic degeneration, tumor cell necrosis or both in prolactinomas.
\end{abstract}

\section{Introduction}

Prolactinoma is the most common hormone-secreting pituitary adenoma encountered in the clinical setting (1). Hyperprolactinemia may result in hypogonadism, infertility and galactorrhea, while larger adenomas can produce mass effects by impinging on local structures $(2,3)$. Whereas most prolactinomas are readily controlled by dopamine agonists (e.g., cabergoline), which activate tumoral dopamine subtype $2\left(D_{2}\right)$ receptors, this is unsuccessful in up to $10 \%$ of patients (4). Resistance to dopamine agonists is commonly defined as a failure to normalize prolactin and a less than $50 \%$ decrease in tumor diameter at a maximal labeled dose of $2.0 \mathrm{mg} /$ week (4). In contrast to prolactinomas in general, which most frequently present as microadenomas in young adult females, cabergoline-resistant prolactinomas are characteristically macroadenomas and $46 \%$ of patients are males; genetic or familial disease is seen in $13 \%$ of resistant cases (5).

The recent guidelines on the management of aggressive pituitary tumors and carcinomas (6) recommend that the highest tolerated dose of dopamine agonists, up to $11.0 \mathrm{mg} /$ week, can be used in patients with dopamineresistant prolactinomas. We define aggressive pituitary tumors as multirecurrent and resistant to multimodal therapy including surgery and radiotherapy (6). However, 
a study by Delgrange et al. showed that although this resistance to the prolactin-lowering effect of cabergoline is often partial and can be overcome in $75 \%$ of the cases by increasing the weekly dose up to $3.5 \mathrm{mg}$; little additional advantage was seen above a threshold of $3.5 \mathrm{mg} /$ week (7). Transsphenoidal surgery (TSS) should also be considered in those tumors, either as total resection or debulking, while radiotherapy is reserved for uncommon patients $(<5 \%)$ whose hyperprolactinemia and tumor cannot be controlled with surgery $(1,8)$. Temozolomide chemotherapy has been used for very aggressive, dopamine-resistant macroprolactinomas, albeit with limited success $(4,6)$.

First-generation somatostatin receptor ligands (SRLs) have not been found to be useful for treating prolactinomas since they bind primarily to somatostatin receptor subtype 2a ( $\mathrm{SST}_{2 \mathrm{a}}$ ), while $\mathrm{SST}_{5}$ is more important with respect to the regulation of prolactin secretion (9). Pasireotide longacting release (PAS-LAR) is a second-generation SRL, which binds to multiple SST receptors, but had particularly high affinity for $\mathrm{SST}_{5}$ receptor (10). Despite the fact that most prolactinomas express $\mathrm{SST}_{5}$ receptors, the effects of first-generation SRLs that target $\mathrm{SST}_{5}$ receptor in in vitro studies are superimposable upon to those of dopamine agonists and most dopamine-resistant prolactinoma cells are resistant to somatostatin analogs that bind to this receptor $(9,11,12)$. However, the clinical experience with PAS-LAR is that it is not restricted to activity via the $\mathrm{SST}_{5}$ receptor alone, as in acromegaly patients who are partially responsive to first-generation SRLs the responsiveness to PAS-LAR seems more driven by $\mathrm{SST}_{2 \mathrm{a}}$ receptor (13), while it is generally assumed that PAS-LAR is more effective when $\mathrm{SST}_{5}$ receptor is predominantly expressed (14).

To date, there has only been one report of a dopamine-resistant prolactinoma treated by PAS-LAR (15). Here we report a highly aggressive, dopamineresistant prolactinoma that had an excellent biochemical and tumor response, including tumor shrinkage and rapid antitumor effects. This case shows that PAS-LAR therapy holds a clinical potential in selective aggressive, dopamine-resistant prolactinomas that express $\mathrm{SST}_{5}$ receptor and appears to be a potential new treatment option before starting temozolomide therapy.

\section{Methods}

\section{Case history}

The proband was a 61-year-old woman referred to our institution for evaluation of a dopamine-resistant prolactinoma. She presented initially to a local hospital at the age of 25 years with secondary amenorrhea and was found to have hyperprolactinemia (levels unavailable). She had no clinical features of hypopituitarism and was not taking any medication. Magnetic resonance imaging (MRI) of the pituitary gland revealed a macroadenoma. She initially received bromocriptine therapy $(2.5 \mathrm{mg}$ three times daily), and the prolactin levels normalized, although her menses were not restored. Six years later, she developed bitemporal hemianopia and was again found to be hyperprolactinemic on bromocriptine therapy. She underwent TSS with the goal of gross-total resection. Postoperatively she had hyperprolactinemia and a tumor remnant. She was placed on bromocriptine again $(2.5 \mathrm{mg}$ three times daily) and was controlled compared with her pre-operative situation. Three years later, the proband presented for a second time with bitemporal hemianopia and hyperprolactinemia during bromocriptine therapy ( $2.5 \mathrm{mg}$ three times daily), and she underwent second TSS with postsurgical conventional radiotherapy (total dose: 50.4 gray (Gy)). During the post-operative period, she developed thyroid and adrenal insufficiency. Postoperatively she had a tumor remnant and hyperprolactinemia that again necessitated bromocriptine therapy ( $2.5 \mathrm{mg}$ three times daily). Again, 6 years later, the bitemporal hemianopia and hyperprolactinemia returned during bromocriptine therapy ( $2.5 \mathrm{mg}$ three times daily), but now she underwent gamma knife radiosurgery (total dose: $15.0 \mathrm{~Gy})$. Cabergoline monotherapy $(0.5 \mathrm{mg} /$ wk) was afterward initiated and increased up to $3.0 \mathrm{mg} /$ week during the next 5 years. During the next 2 years, her prolactin levels were normalized, but eventually therapy failed and both hyperprolactinemia and clinically relevant tumor growth occurred again (prolactin level $227.36 \mathrm{ng}$ per milliliter ( $4837 \mathrm{mU}$ per liter), tumor size $2549 \mathrm{~mm}^{3}$ ). It is important to note that for all surgical and radiotherapy interventions, the reason of conduct was both hyperprolactinemia and bitemporal hemianopia, demonstrating the persistent recurrence of this tumor.

At this point, the proband was referred to our institution. Histology of the excised specimen from first and second pituitary surgery were evaluated. Histology of the first surgical excised specimen revealed an adenoma, consisting of cells with moderate amounts of eosinophilic fine granular cytoplasm and nuclei with fine granular chromatin. Almost all tumor cells were positively stained for prolactin (Fig. 1), while there was no staining for GFAP, ACTH, GH, FSH, LH and TSH. Ki-67 (Mib-1) staining showed 5-10\% expression in the tumoral cells and no overexpression of p53 (Fig. 1) (16). The pituitary tissue was immunostained for $\mathrm{SST}_{2 \mathrm{a}}$ and $\mathrm{SST}_{5}$ receptor using the rabbit 
monoclonal anti-SST ${ }_{2 a}$ receptor antibody clone UMB-1 (SS-8000; BioTrend, Köln, Germany) at a dilution of 1:50 and the rabbit monoclonal anti-SST ${ }_{5}$ receptor antibody clone UMB-4 at a dilution of 1:400 (ab109495; Abcam, Cambridge, United Kingdom). SST receptor subtyping was evaluated using an immunoreactivity score (IRS) $(17,18)$, showing membranous expression of IRS 9 for $\mathrm{SST}_{2 \mathrm{a}}$ receptor and IRS 12 for SST $_{5}$ receptor (Fig. 1). We classified this tumor as grade $2 \mathrm{~b}$, indicating an invasive and a proliferative tumor, according to Trouillas and colleagues (19) as the tumor was a macroadenoma, stained for prolactin, invaded the cavernous sinus and showed proliferative markers (Ki-67 $5-10 \%$ and eight mitotic figures with ten high power field). Immunohistochemistry of the residual tumor revealed, in contrast to first surgery, membranous expression score of IRS 6 for $\mathrm{SST}_{2 \mathrm{a}}$ receptor, whereas $\mathrm{SST}_{5}$ receptor remained IRS 12 (data not shown). The difference in $\mathrm{SST}_{2 \mathrm{a}}$ expression after the second surgery could be due to molecular events in the
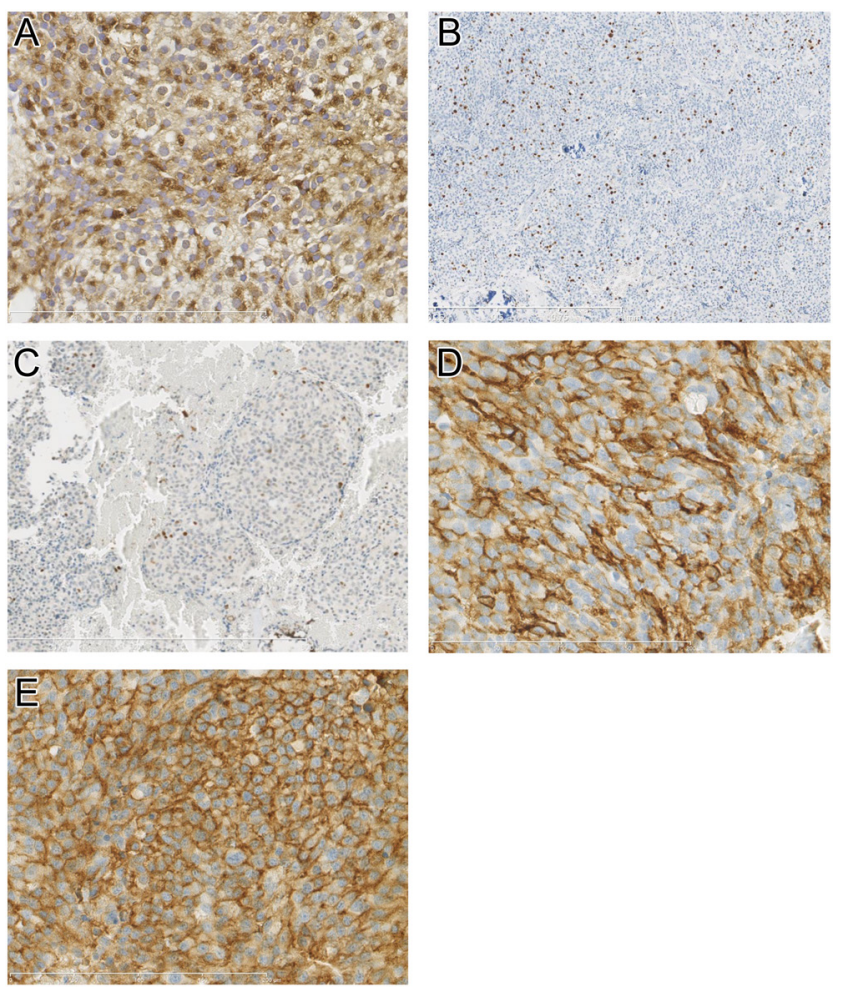

\section{Figure 1}

Following first pituitary surgery. Immunohistochemistry for prolactin (A) showing strong expression of prolactin in most lesional cells, Ki-67 (Mib-1) (B) showing staining in 5-10\% of the lesional cells without overexpression of p53 (C). Immunohistochemistry for $\mathrm{SST}_{2 \mathrm{a}}$ receptor (D) showing membranous staining IRS 9, SST $_{5}$ receptor (E) with IRS 12 after first surgery. IRS, immunoreactivity score. tumor, which contribute to the change in tumor behavior. However, the molecular events responsible for reduced SSTs receptor expression are still largely unknown (20). The proliferative markers from the second surgery did not differ from the first. There was no family history of pituitary or endocrine neoplasia and investigations for germline mutations in the aryl hydrocarbon receptor-interacting protein $(A I P)$, multiple endocrine neoplasia type 1 (MEN1), cyclin-dependent kinase inhibitor 1B (CDKN1B) genes and multiplex ligation-dependent probe amplification (MLPA) studied for deletions in these genes detected no abnormalities. Prolactin levels in response to different medical therapies are shown in Fig. 2. At follow-up, she was treated with a higher dosage of cabergoline up to $5.0 \mathrm{mg} /$ week for 3 months, while prolactin levels along with tumor size tended to increase still further. To determine whether maximum dose of co-treatment with first-generation SRL lanreotide autogel $120 \mathrm{mg} / \mathrm{month}$ would have an additional effect, she took combination therapy with lanreotide and cabergoline for 10 months. Hyperprolactinemia and clinically relevant tumor growth, however, remained unchanged and cabergoline dose was increased further up to $7.0 \mathrm{mg} /$ week (7), while lanreotide was discontinued. After 16 months of follow-up, this high dose of cabergoline failed

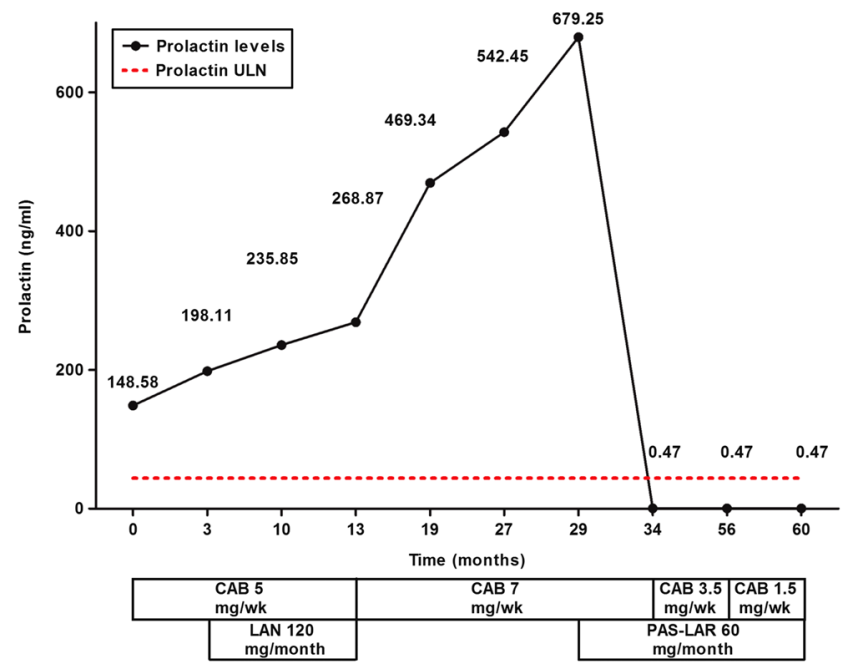

\section{Figure 2}

Prolactin levels in response to different medical therapies during the academic clinical follow-up of the proband. Time (months) $=0$ represents the time point of the referral to our institution. Data are shown until 60 months. CAB, cabergoline; LAN, lanreotide autogel; $\mathrm{ng} / \mathrm{mL}$, nanogram per milliliter; PAS-LAR, pasireotide long-acting release; ULN, upper limit of normal; wk, week. A full colour version of this figure is available at https://doi.org/10.1530/EJE-19-0279. 
to normalize prolactin levels nor had it reduced tumor volume (there were no visual field defects).

We decided to start PAS-LAR in combination with cabergoline to determine whether it could achieve biochemical and tumor control, particularly given the presence of multiple SST receptors in tumor specimens. Written informed consent was obtained from the proband for genetic studies and for publication of this case report, in accordance with the Declaration of Helsinki.

\section{Treatment}

PAS-LAR was initiated at a dose of $60.0 \mathrm{mg} / \mathrm{month}$, while cabergoline was continued at $7.0 \mathrm{mg} /$ day. Regular electrocardiograms and biochemical monitoring were performed, including prolactin and insulin-like growth factor I (IGF-I) levels, fasting plasma glucose (FPG) and glycosylated hemoglobin (HbA1c) levels and analysis of renal and liver function. The proband has no preexisting impaired glucose metabolism before initiating PAS-LAR according to the American Diabetes Association (ADA) criteria ${ }^{21}$. MRI examinations were collected for central reading and an experienced neuroradiologist (K P) evaluated MRIs in the Picture Archive Communication System (PACS, Sectra®, Linköping, Sweden).

\section{Results}

\section{Biochemical response to PAS-LAR}

The response to combination therapy with PAS-LAR and cabergoline in the proband is shown in Fig. 2 . Co-treatment with PAS-LAR and cabergoline achieved prolactin normalization within 2 months, which has been sustained to date for a duration of 31 months (Fig. 2). The dose of cabergoline was gradually tapered down from $3.5 \mathrm{mg}$ /week after 5 months to $1.5 \mathrm{mg}$ /week after 27 months of PAS-LAR, because echocardiographic screening revealed the new onset of clinically significant valvular heart disease. PAS-LAR was well tolerated and has not been complicated by common side effects such as hyperglycemia, diarrhea, abdominal pain, nausea or other related side effects (22). HbA1c levels increased from $5.4 \%$ (normal value, $<7 \%$ ) before the start of PASLAR to $6.2 \%$ after 6 months of treatment and remained relatively stable at $6.3 \%$ after 18 months of treatment without antidiabetic therapy. Moreover, FPG levels remained $<5.7 \mathrm{mmol} / \mathrm{L}$ during PAS-LAR, indicating normal glucose tolerance according to ADA criteria (21).
Other laboratory assessments have shown reduced levels of IGF-I ( 25.9 at baseline-normal value, $<24.3 \mathrm{nmol} / \mathrm{L}$; to $6.1 \mathrm{nmol} / \mathrm{L}$ after 6 months of treatment; normal value, $<22.0 \mathrm{nmol} / \mathrm{L}$ ) and normal renal and liver function during the follow-up. At this point, she is still continuing the combination therapy with PAS-LAR $(60.0 \mathrm{mg} / \mathrm{month})$ and cabergoline (1.5 mg/week).

\section{Tumor response to PAS-LAR}

The volumetric tumor response on gadolinium-enhanced $\mathrm{T}_{1}$-weighted MRI during PAS-LAR initiation are shown in Fig. 3. PAS-LAR in combination with low-dose cabergoline markedly reduced the tumor size: the tumor volume reduced from $4660 \mathrm{~mm}^{3}$ before initiation of PAS-LAR to $3900 \mathrm{~mm}^{3}$ during 5 months, halved to $1800 \mathrm{~mm}^{3}$ during 13 months and reduced further to $1300 \mathrm{~mm}^{3}$ during 23 months of treatment (Fig. 3).

Interestingly, using the visual assessment and the T1-signal intensity of the adenoma, we observed an increase in T1-signal heterogeneity of the adenoma. This was particularly clear on the MRI performed 5 months after initiating PAS-LAR therapy (Fig. 3). Moreover, visual assessment and the quantification of the T2-weighted signal by region of interest (ROI) measurement of the adenoma showed a higher $\mathrm{T} 2$ signal intensity ratio during treatment: ROI adenoma/gray matter ratio was 0.89 at baseline, increased to 1.47 during 13 months of treatment and remained increased during 23 months of PAS-LAR treatment in combination with low-dose cabergoline (Fig. 3). In general, heterogeneity on T1- and a T2-hyperintense signal indicates cystic degeneration, tumor cell necrosis, or both, which suggest an antitumor effect of PAS-LAR. Signs for cystic degeneration, tumor cell necrosis or both, were particularly clear on the MRI performed 5 months after initiating PAS-LAR therapy (Fig. 3).

\section{Discussion}

The management of dopamine-resistant and/or aggressive prolactinomas poses a therapeutic challenge. The successful use of PAS-LAR treatment in combination with low-dose cabergoline in a highly aggressive, dopamineresistant prolactinoma that expressed $\mathrm{SST}_{5}$ receptor, reported here, appears to be a potential new treatment option before starting temozolomide therapy.

The decision to start with PAS-LAR was made by a multidisciplinary team after concluding that radiotherapy 


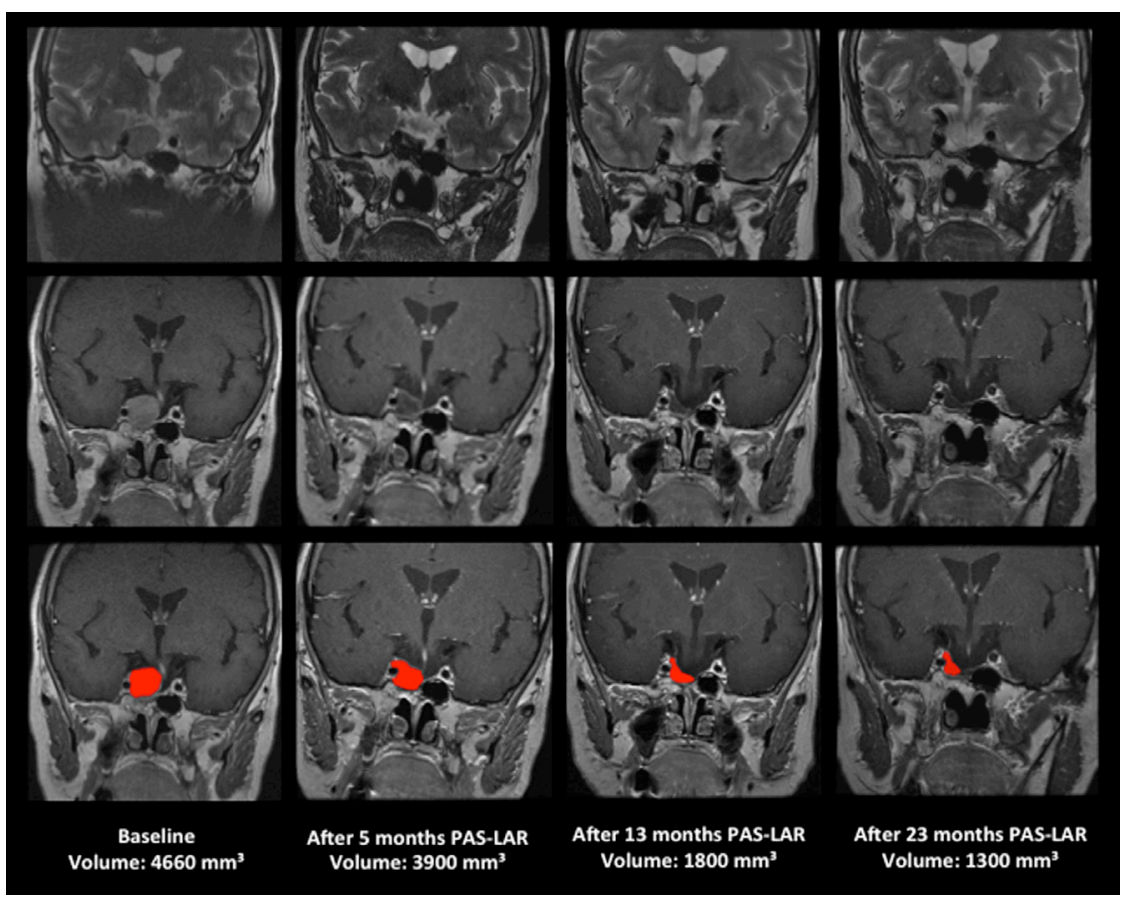

\section{Figure 3}

MRI scans showing T1 - and T2-signal intensity, and tumor shrinkage during treatment with PAS-LAR in combination with low-dose cabergoline. Gadoliniumenhanced T1 and T2-weighted MRI scans obtained before initiation of PAS-LAR therapy, showing a large prolactinoma (left scan, tumor marked in red) during 5, 13 and 23 months of treatment, with marked reduction of the mass (second, third and fourth scan, tumor marked in red). Both visual assessment and the quantification of the T2-weighted signal by ROI measurement of the adenoma shows a higher T2-signal intensity during PAS-LAR treatment. PAS-LAR, pasireotide long-acting release; $\mathrm{ROI}$, region of interest.

would not be a treatment option since maximal dose of radiotherapy had been reached. As mentioned above, radiotherapy is reserved as a treatment option before starting with temozolomide chemotherapy (radiotherapy, however, was not performed in the recent case reported by Lasolle and colleagues (15)). Moreover, surgery had previously failed to be curative on multiple occasions and cabergoline resistance was worsening and additional medical treatment was likely to be needed. An important argument supporting a trial use of PAS-LAR in combination with cabergoline was the absence of visual field defects, which provided a window of opportunity.

At the start of PAS-LAR, cabergoline therapy was continued to ensure the evaluation of efficacy only applied to the addition of PAS-LAR therapy. Cabergoline combined with a $\mathrm{SST}_{5}$ receptor analog may have a possible partial synergistic effect in suppressing prolactin secretion (9). However, when the dose of cabergoline was gradually tapered down in our proband, long-term biochemical and tumor response has been sustained to date, implying that PAS-LAR is a key player. Since cabergoline was not associated with an antitumor effect and induced clinically significant valvular heart disease in our proband, the multidisciplinary team decided last month to stop cabergoline therapy.

Although Raverot and colleagues (6) recommend that the highest tolerated dose of cabergoline should be used in patients displaying dopamine-resistant prolactinomas, this approach is justified as long as there is continued response to the increased dose and no adverse effects.
Therefore, we decided not to increase the dosage further beyond $7.0 \mathrm{mg} /$ week, because both her prolactin levels and tumor volume were unresponsive to the cabergoline dose increases. This was expected, since dopamine-resistant prolactinomas often express a lower number of $\mathrm{D}_{2}$ receptors, explaining the only partial effect of dopamine agonists $(9,23)$. Furthermore, high doses of cabergoline carry the risk of cardiac valvular regurgitation $(1,24,25)$, which was seen in this patient. Cardiac fibrosis of heart leaflets appears to be an irreversible process. To minimize the exposure to cabergoline, one could argue that PASLAR therapy holds potential in patients where high-dose ( $>3.0 \mathrm{mg} /$ week) cabergoline treatment is indicated to suppress the prolactinoma.

Current evidence indicates that PAS-LAR therapy seems unlikely to be effective since most of dopamineresistant prolactinomas appear to express no or low levels of $\mathrm{SST}_{5}$ receptor and are resistant to second-generation SRLs that bind to this receptor (9). The good response to PAS-LAR therapy in our proband may be explained by the remarkable high expression of $\mathrm{SST}_{5}$ receptor levels (IRS 12) in the prolactinoma. In the case from Lasolle et al., SST receptor subtyping was evaluated using the percentage of positive cells and not the staining intensity (15). The same IRS scoring system can be applied for $\mathrm{SST}_{5}$ receptor expression in their case, and the product of the percentage of positive stained cells (2: 10-50\%) and the staining intensity (2: moderate staining) would amount to a maximum IRS score of 4 , which corresponds with moderate expression. 
Therefore, our results support the possibility of good clinical responses to PAS-LAR therapy in prolactinomas for which $\mathrm{SST}_{5}$ receptor expression is significant.

Based on our clinical experiences treating dopamineresistant prolactinoma patients with cabergoline and firstgeneration SRL combination therapy, we observed that in several cases co-treatment with SRLs may suppress prolactin levels. However, after 10 months of first-generation SRL therapy with lanreotide, there was no effect in suppressing prolactin secretion in our case. In addition, lower potency of the first-generation SRL in reducing prolactin secretion is related to lower $\mathrm{SST}_{2 \mathrm{a}}$ receptor levels (9); intermediate levels of $\mathrm{SST}_{2 \mathrm{a}}$ receptor (IRS 6) were present on the prolactinoma in our proband after the second operation.

In contrast to the previous case (15), we observed tumor size reduction after PAS-LAR administration. Although activation of specific SST subtypes may explain this discrepancy, as the mechanisms responsible for inhibition of cell proliferation in pituitary tumors are mediated by both $\mathrm{SST}_{2}$ and $\mathrm{SST}_{5}$ receptor activation (26), and the observed tumor shrinkage can be assigned to the higher expression of these SSTs receptors in our case.

Interestingly, as shown in our and the previous case (15), PAS-LAR therapy might induce cystic degeneration, tumor cell necrosis or both. Coopmans and co-workers, however, also recently reported increased T2-weigthed MRI signal of the adenoma in 14 (30.0\%) of 47 acromegaly patients suggestive for cystic degeneration, tumor cell necrosis or both, during PAS-LAR treatment (27). No newonset anterior pituitary deficiencies were observed in our proband, the previous case (15) or in the acromegaly cohort (27). Therefore, we recommend close monitoring of pituitary tumor status, alongside regular assessment of prolactin concentrations, and, in case of substantial necrosis to reconsider the treatment regimen.

Among the SST receptor subtypes only $\mathrm{SST}_{2}$ and $\mathrm{SST}_{3}$ might be responsible for the somatostatin-induced apoptosis. Whether a subgroup of patients will benefit from targeting these receptors with a multireceptor ligand with an improved affinity for $\mathrm{SST}_{3}$ receptor remains to be elucidated. However, immunohistochemistry with the rabbit monoclonal antihuman $\mathrm{SST}_{3}$ receptor antibody UMB-5 were not performed due to limited specificity for the $\mathrm{SST}_{3}$ receptor (28).

A noted side effect of PAS-LAR is the frequent development of hyperglycemia. The proband had good glycemic control while receiving PAS-LAR therapy: although HbA1c levels did rise after PAS-LAR administration, still she has not developed diabetes according to the ADA criteria (21). This might be due to the fact that she has no pre-existing impaired glucose metabolism before initiating
PAS-LAR, while elevated HbA1c and FPG levels at baseline are strong predictors for developing hyperglycemia among acromegaly patients (29).

This individual patient report further underlines the role of $\mathrm{SST}_{5}$ receptor in mediating its suppressive effect on prolactinomas. However, the potential clinical importance of these findings should be considered as relating to a very specific group of patients, namely those with aggressive prolactinomas expressing moderate to high levels of $\mathrm{SST}_{5}$ receptor. In this setting PAS-LAR responses can include normalization of prolactin levels, tumor shrinkage, and perhaps cystic degeneration or tumor cell necrosis.

In conclusion, this case shows that in selective patients with aggressive and dopamine-resistant prolactinomas, PAS-LAR therapy holds clinical potential in prolactinomas that express high affinity for $\mathrm{SST}_{5}$ receptor and appears to be a potential new treatment option before starting temozolomide therapy. In addition, PAS-LAR therapy may induce cystic degeneration, tumor cell necrosis, or both, of pituitary tumors in prolactinomas.

\section{Declaration of interest}

E C Coopmans, S W F van Meyel, K J Pieterman, J A van Ipenburg and E Donga have nothing to disclose. LJ Hofland received investigator-initiated research grants from Novartis and Ipsen. A F Daly is a consultant for Amryt Pharma, holds stock in Amryt Pharma and has received grants and/or speakers fees from Pfizer and Ipsen. A Beckers is a consultant for Ipsen Pharma and received research funding from Ipsen Pharma, Novartis and Pfizer. A J van der Lely is a consultant for Pfizer Inc., and received speaker fees from Novartis Pharma, Ipsen Pharma and Pfizer. S J C M M Neggers received research grants and speakers fees from Ipsen Pharma, Novartis Pharma, Pfizer Inc. and consulting fees from Ipsen Pharma.

\section{Funding}

This research did not receive any specific grant from any funding agency in the public, commercial or not-for-profit sector.

\section{References}

1 Melmed S, Casanueva FF, Hoffman AR, Kleinberg DL, Montori VM, Schlechte JA, Wass JAH \& Endocrine Society. Diagnosis and treatment of hyperprolactinemia: an Endocrine Society clinical practice guideline. Journal of Clinical Endocrinology and Metabolism 201196 273-288. (https://doi.org/10.1210/jc.2010-1692)

2 Gillam MP, Molitch ME, Lombardi G \& Colao A. Advances in the treatment of prolactinomas. Endocrine Reviews 200627 485-534. (https://doi.org/10.1210/er.2005-9998)

3 Klibanski A. Clinical practice. Prolactinomas. New England Journal of Medicine 2010362 1219-1226. (https://doi.org/10.1056/ NEJMcp0912025)

4 Molitch ME. Management of medically refractory prolactinoma. Journal of Neuro-Oncology 2014117 421-428. (https://doi. org/10.1007/s11060-013-1270-8)

5 Vroonen L, Jaffrain-Rea ML, Petrossians P, Tamagno G, Chanson P, Vilar L, Borson-Chazot F, Naves LA, Brue T, Gatta B et al. Prolactinomas resistant to standard doses of cabergoline: a 
multicenter study of 92 patients. European Journal of Endocrinology 2012167 651-662. (https://doi.org/10.1530/EJE-12-0236)

6 Raverot G, Burman P, McCormack A, Heaney A, Petersenn S, Popovic V, Trouillas J, Dekkers OM \& European Society of E. European Society of Endocrinology Clinical Practice Guidelines for the management of aggressive pituitary tumours and carcinomas. European Journal of Endocrinology 2018178 G1-G24. (https://doi. org/10.1530/EJE-17-0796)

7 Delgrange E, Daems T, Verhelst J, Abs R \& Maiter D. Characterization of resistance to the prolactin-lowering effects of cabergoline in macroprolactinomas: a study in 122 patients. European Journal of Endocrinology 2009160 747-752. (https://doi.org/10.1530/EJE-090012)

8 Casanueva FF, Molitch ME, Schlechte JA, Abs R, Bonert V, Bronstein MD, Brue T, Cappabianca P, Colao A, Fahlbusch R et al. Guidelines of the Pituitary Society for the diagnosis and management of prolactinomas. Clinical Endocrinology $2006 \mathbf{6 5}$ 265-273. (https://doi.org/10.1111/j.1365-2265.2006.02562.x)

9 Jaquet P, Ouafik L, Saveanu A, Gunz G, Fina F, Dufour H, Culler MD, Moreau JP \& Enjalbert A. Quantitative and functional expression of somatostatin receptor subtypes in human prolactinomas. Journal of Clinical Endocrinology and Metabolism 199984 3268-3276. (https:// doi.org/10.1210/jcem.84.9.5962)

10 Schmid HA. Pasireotide (SOM230): development, mechanism of action and potential applications. Molecular and Cellular Endocrinology 2008286 69-74. (https://doi.org/10.1016/j.mce.2007.09.006)

11 Ibanez-Costa A, Rivero-Cortes E, Vazquez-Borrego MC, Gahete MD, Jimenez-Reina L, Venegas-Moreno E, de la Riva A, Arraez MÁ, Gonzalez-Molero I, Schmid HA et al. Octreotide and pasireotide (dis) similarly inhibit pituitary tumor cells in vitro. Journal of Endocrinology 2016231 135-145. (https://doi.org/10.1530/JOE-16-0332)

12 Fusco A, Gunz G, Jaquet P, Dufour H, Germanetti AL, Culler MD Barlier A \& Saveanu A. Somatostatinergic ligands in dopaminesensitive and -resistant prolactinomas. European Journal of Endocrinology 2008158 595-603. (https://doi.org/10.1530/ EJE-07-0806)

13 Muhammad A, Coopmans EC, Gatto F, Franck SE, Janssen JAMJL, van der Lely AJ, Hofland LJ \& Neggers SJCMM. Pasireotide responsiveness in acromegaly is mainly driven by somatostatin receptor subtype 2 expression. Journal of Clinical Endocrinology and Metabolism 2019104 915-924. (https://doi.org/10.1210/jc.201801524)

14 Iacovazzo D, Carlsen E, Lugli F, Chiloiro S, Piacentini S, Bianchi A, Giampietro A, Mormando M, Clear AJ, Doglietto F et al. Factors predicting pasireotide responsiveness in somatotroph pituitary adenomas resistant to first-generation somatostatin analogues: an immunohistochemical study. European Journal of Endocrinology 2016 174 241-250. (https://doi.org/10.1530/EJE-15-0832)

15 Lasolle H, Vasiljevic A, Borson-Chazot F \& Raverot G. Pasireotide: A potential therapeutic alternative for resistant prolactinoma. Annales d'Endocrinologiel (Paris) 2018. (https://doi.org/10.1016/j. ando.2018.07.013)

16 Louis DN, Ohgaki H, Wiestler OD \& Cavenee WK. WHO Classification of Tumours of the Central Nervous System, IARC WHO Classification of Tumours, Revised 4th edn, Volume 1. The International Agency for Research on Cancer, 2016, 131: 803. (https://doi.org/10.1007/ s00401-016-1545-1)

17 Remmele W \& Stegner HE. Recommendation for uniform definition of an immunoreactive score (IRS) for immunohistochemical estrogen receptor detection (ER-ICA) in breast cancer tissue. PathologiaEuropaea 19878 138-140.

18 Gatto F, Feelders RA, van der Pas R, Kros JM, Waaijers M, SprijMooij D, Neggers SJ, van der Lelij AJ, Minuto F, Lamberts SW et al. Immunoreactivity score using an anti-sst $2 \mathrm{~A}$ receptor monoclonal antibody strongly predicts the biochemical response to adjuvant treatment with somatostatin analogs in acromegaly. Journal of Clinical Endocrinology and Metabolism 201398 E66-E71. (https://doi. org/10.1210/jc.2012-2609)

19 Trouillas J, Roy P, Sturm N, Dantony E, Cortet-Rudelli C, Viennet G, Bonneville JF, Assaker R, Auger C, Brue T et al. A new prognostic clinicopathological classification of pituitary adenomas: a multicentric case-control study of 410 patients with 8 years postoperative follow-up. Acta Neuropathologica 2013126 123-135. (https://doi.org/10.1007/s00401-013-1084-y)

20 Peverelli E, Treppiedi D, Giardino E, Vitali E, Lania AG \& Mantovani G. Dopamine and somatostatin analogues resistance of pituitary tumors: focus on cytoskeleton involvement. Frontiers in Endocrinology 20156 187-187. (https://doi.org/10.3389/ fendo.2015.00187)

21 American Diabetes Association. In this issue of diabetes care. Diabetes Care 201740 (Supplement 1) 1-2. (https://doi.org/10.2337/ dc17-ti01)

22 Signifor LAR. Summary of Product Characteristics: Basel: Novartis Pharma AG; 2014.

23 Caccavelli L, Feron F, Morange I, Rouer E, Benarous R, Dewailly D, Jaquet P, Kordon C \& Enjalbert A. Decreased expression of the two D2 dopamine receptor isoforms in bromocriptine-resistant prolactinomas. Neuroendocrinology 199460 314-322. (https://doi. org/10.1159/000126764)

24 Vroonen L, Lancellotti P, Garcia MT, Dulgheru R, RubioAlmanza M, Maiga I, Magne J, Petrossians P, Auriemma R, Daly AF et al. Prospective, long-term study of the effect of cabergoline on valvular status in patients with prolactinoma and idiopathic hyperprolactinemia. Endocrine 201755 239-245. (https://doi. org/10.1007/s12020-016-1120-5)

25 Caputo C, Prior D \& Inder WJ. The need for annual echocardiography to detect cabergoline-associated valvulopathy in patients with prolactinoma: a systematic review and additional clinical data. Lancet. Diabetes and Endocrinology 20153 906-913. (https://doi.org/10.1016/S2213-8587(14)70212-8)

26 Danila DC, Haidar JN, Zhang X, Katznelson L, Culler MD \& Klibanski A. Somatostatin receptor-specific analogs: effects on cell proliferation and growth hormone secretion in human somatotroph tumors. Journal of Clinical Endocrinology and Metabolism 200186 2976-2981. (https://doi.org/10.1210/jcem.86.7.7620)

27 Coopmans EC, van der Lely AJ, Schneiders JJ \& Neggers SJCMM. Potential antitumour activity of pasireotide on pituitary tumours in acromegaly. Lancet Diabetes and Endocrinology $20197425-426$. (https://doi.org/10.1016/S2213-8587(19)30113-5)

28 Korner M, Waser B, Christ E, Beck J \& Reubi JC. A critical evaluation of sst3 and sst5 immunohistochemistry in human pituitary adenomas. Neuroendocrinology 2018106 116-127. (https://doi. org/10.1159/000472563)

29 Schmid HA, Brue T, Colao A, Gadelha MR, Shimon I, Kapur K, Pedroncelli AM \& Fleseriu M. Effect of pasireotide on glucose- and growth hormone-related biomarkers in patients with inadequately controlled acromegaly. Endocrine 201653 210-219. (https://doi. org/10.1007/s12020-016-0895-8)

Received 12 April 2019

Revised version received 1 June 2019

Accepted 5 June 2019 